\title{
View from New Zealand
}

Dr Heather Buchan, chief medical officer for Otago, describes some of the recent changes in New Zealand's health care system.

New Zealanders have lost confidence in their public health care system as the government struggles with the common theme in the developed world of how to cope with expanding demand and scarce resources. Public hospitals struggle to contain costs, waiting lists have lengthened, and some types of surgery are effectively unavailable in the public sector. Access to health services now depends on where people live, their income, and their ability to obtain private health insurance. Equity has disappeared.

There are concerns about the appropriateness of some types of care and about the regulation and control of medical practice. A succession of scandals about the management of psychiatric patients and widely publicised revelations concerning the treatment of cervical cancer at a major teaching hospital have profoundly shaken public faith in the integrity of the public health system.

Health care workers tend to blame inadequate government funding. Politicians respond by criticising efficiency and management. In five years New Zealand has had four ministers of health. Redesign of the health service has been endlessly discussed and relentlessly pursued. Restructuring is a familiar, almost continuous, activity for those working in the health service; the previous major reorganisation was completed in 1989.

The change of government in late 1990 brought the prospect of further changes. The Minister of Health set up a small taskforce to advise him on options for future funding and provision of health services. Individual responsibility for health and health care; promoting choice and competition; limitation of central government expenditure, and targetting help to those least able to provide for themselves were prime objectives. A massive public relations effort, which included briefings for key people on the night of the budget, reinforced the message of radical reform. The document Your
Health and the Public Health (popularly known as the green and white paper) was released on budget night.

\section{Latest proposals}

The announcement that purchasing and provision of health care were to be separated had been widely predicted However, abolition of the fourteen area health boards, only recently brought into existence after years of debate and public consultation, was more of a shock to many. As a first step in the transition to a new structure the elected and appointed members of each area health board were dismissed on budget night and replaced by a commissioner.

Four regional health authorities will be formed to purchase core health services from a range of public, private, and voluntary providers. The budget for purchasing will be population based and capped. Contracts must concentrate not just on low cost provision of care but also on the quality of the service to be provided. Those dissatisfied with the performance and purchasing decisions of their regional health authority will be able to opt out and take their entitlement to government funding to a private health care plan, which must offer customers a full range of core health services provided by itself or purchased from other agencies.

Large public hospitals and associated services will become crown health enterprises; they will be responsible to a separate minister, have management boards, and be required to show a return on assets. Local communities will be offered the opportunity to take over smaller community hospitals and services and run them as community trusts. Population based health services such as health promotion and disease prevention will be funded separately. Purchasing and provision of these services will also be split.

The core health services defined in the green and white paper as those to which "everyone should have access, on affordable terms and without unreasonable waiting time" have yet to be specified. A national advisory committee has been appointed to consult with the public and to decide on these services, which all regional health authorities and health care plans must purchase. Core health services will not neccessarily be free. Another change in the budget announcements was the extension of user part charges to secondary care. User charges are a long established feature of primary medical care in New Zealand. Patients pay general practitioners on a fee for service basis. The government provides a subsidy which varies (from $0-100 \%$ ) according to patient characteristics. Part charges are also levied on presciptions and some types of diagnostic tests.

The Minister of Health believes that user part charges encourage greater personal responsibility for health and discourage unnecessary use of health services. Many patients will now pay for public hospital services which traditionally have been free to all New Zealanders within the welfare state system. The level of user charge will depend on income and there is a complex list of exemptions from charges and limits that will apply for any one family in any one year. The administrative complexities of the new system have not escaped notice. The government has rejected the use of computerised "smart" cards in the face of opposition from civil rights groups and because of its own reluctance to pass comprehensive privacy legislation Consequently, six separate cards will be needed to identify those eligible for exemptions.

Uncertainties surround the future role of insurance. At present, private insurance schemes reimburse user part charges - providing so called "gap" insurance - or provide supplementary insurance for procedures or services subject to long waiting lists in the public sector. Insurance premiums have already risen steeply in anticipation of the introduction of user part charges for hospital care. The argument that user charges discourage wasteful use of health services runs into difficulties with "gap" insurance. Once people have paid an insurance premium they have no incentive to limit their use of services.

Public submissions have been requested about only two aspects of the changes: how core health services should be defined and
Zealand

Heather Buchan, chief medical officer 
whether future funding of the health services should be through a tax based or social insurance type scheme. The other changes to the health sector announced in the green and white paper are now government policy and are being implemented. Special boards and directorates have been established to manage the restructuring, but no extra money is being made available to Vote Health to fund the changes Negotiation and monitoring of contracts will involve significant commitment of resources.

\section{Change for the better?}

Will these changes bring the promised improvements in access, efficiency, and consumer responsiveness? With so many features of the new system as yet uncertain, imprecise, or undecided this is difficult to assess. But there are some concerns.

The decision to allow people to reject a regional health authority as a purchaser of health care and transfer entitled funding to another health care plan carries considerable risks. If health care plans accept only healthy, low risk clients and do not provide care or treatment which is likely to be expensive, then regional health authorities will be left as the funders of last resort. The green and white paper specifies two main strategies to prevent this situation occurring. The first is likely to be an actuarial nightmare. People predicted to have greater needs for health care will have a proportionately larger sum of money transferred to the plan; for those on low income the entitlement will exceed the share of taxes they pay for health services. The second strategy relates to the range of services to be offered by a health care plan. Health care plans are expected to manage the total health care requirements of their clients and must provide all services included in the core health services.

The success of these strategies is heavily dependent on how core health services are defined - in particular, the extent to which the type, level, and quality of these services is detailed. The range of clients a health care plan is likely to accept will be determined by the amount of the transferrable subsidy. How competition in purchasing will affect health care delivery and quality depends on decisions yet to be made about the regulations covering the operation of health care plans and what will happen if these plans become insolvent.

If people purchase insurance cover from their own health plan the problem of "gap" insurance may be solved as health care plans will have an interest in limiting unnecessary service use. Health care plans, unlike regional health authorities, will be permitted to be both purchasers and providers of primary and secondary care.

It is unclear whether regional health authorities will be allowed to offer their own insurance schemes. If so, purchasing decisions will cease to be related to the perceived health needs of the total population and will be reorientated towards capturing market share. If not, the possibility increases that they will become organisations which cater only for those who, because of income or health status, are unable to find an alternative.

Containing the level of primary care spending in ways acceptable to the medical profession will be a major challenge for purchasers. Previous efforts to change the subsidised fee for service payment arrangements have been unsuccessful. The willingness of general practitioners to enter into alternative arrangements with regional health authorities or health care plans will be a critical factor in determining whether the government's vision of integrated managed care is sustained.

Funding of education and training of health professionals is also being reviewed. Selected providers will be explicitly contracted and funded to provide clinical training. The recent series of strikes by hospital resident medical officers over conditions of employment has focused the attention of hospital managers on the distinction between service and training. The application of market theory to health care has also led to a questioning of the role of medical profession and of the specialty colleges. Rules and regulations concerning requirements for training, viewed by those within the medical profession as a mechanism for protecting the public and maintaining quality, are interpreted by others as costly mechanisms to preserve power, income, and status by creating barriers to entry.

\section{The quality component}

Debate is continuing on how the changes will affect access to health care in terms of which services will be defined in the core and whether hospital charges will create financial barriers to care. Access to health care is only one aspect of quality. The green and white paper states that other quality criteria will receive increased emphasis in the reformed health system. Mention is made of overseas experience that providers may undertake to compete for funding on quality, rather than price. The government obviously hopes that local providers will decide that this is good business strategy. Emphasis on improvement in quality of service as well as low cost provision is supposed to be included in contracts regional health authorities make with providers. Mechanisms for monitoring quality, such as health care accreditation, licensing of facilities and health care professionals, peer review, monitoring of outcome, and quality improvement programmes, are mentioned in the green and white paper - in one sentence. Clearly, much further work needs to be done.

The government has given assurances that quality of care will not suffer as a result of the health reforms, and more detail about the definition of quality and how it is to be monitored is expected from implementation boards and directorates. But one report commissioned by the National Interim Provider Board from a consultancy firm has suggested that regulated quality assurance mechanisms should be seen as ancillary to the control provided by the competitive process.

Moves to develop formal quality assurance had begun before the reforms were announced. A New Zealand organisation for health care accreditation has been active for some time, and quality programmes for mental health services have figured prominently as a result of perceived deficiencies in those services. Health consultancy groups obviously expect interest in audit and monitoring of outcome to grow and are eagerly promoting their services to the health sector.

Changes in the NHS in Britain are being followed with great interest in New Zealand. The health reforms in both countries share some features, but the restructuring of New Zealand's health service promises more radical change in a shorter space of time with a less predictable outcome. We are not yet sure where that bold leap will land us. 